\title{
Relações entre parte aérea e raízes em povoamentos de teca ${ }^{1}$
}

\author{
Maurel Behling $2^{2 *}$, Rafaella Teles Arantes Felipe $e^{3}$, Jaqueline Bento Farias ${ }^{2}$, \\ Géssica de Carvalho², Júlio César Lima Neves ${ }^{3}$
}

$10.1590 / 0034-737 X 201865060001$

\section{RESUMO}

Há pouca informação disponível sobre a relação entre folhas e raízes de teca, cultivada no Brasil. O objetivo deste trabalho foi avaliar se a biomassa dos componentes da parte aérea e a área foliar são bons estimadores da biomassa e da superfície de raízes, em povoamentos de teca (Tectona grandis). Na amostragem, realizada em árvores de teca, com 17 e 90 meses de idade, em parcelas estabelecidas em talhões comerciais em Tangará da Serra, MT, foram individualizados os componentes raízes, folhas, galhos e tronco, determinando-se, posteriormente, suas biomassas secas, AFE (área foliar específica) e ARE (área radicular específica). A superfície da folha de uma árvore jovem é quatro vezes maior que a superfície de uma folha de árvore adulta de teca. A superfície de raízes finas $(<2 \mathrm{~mm})$ das árvores adultas é quatro vezes maior que a superfície de raízes médias (2 a $5 \mathrm{~mm}$ ). AAFE foi de $13,14 \mathrm{~m}^{2} \mathrm{~kg}^{-1} \mathrm{e}$ a ARE de $13,86 \mathrm{~m}^{2} \mathrm{~kg}^{-1}$, indicando eficiência semelhante quanto à utilização do $\mathrm{C}$ na produção de superfícies para aquisição de radiação solar, água $\mathrm{e}$ nutrientes e, ainda, que há sincronia na alocação de $\mathrm{C}$ entre folhas e raízes finas para formação de novos tecidos foliares e radiculares. O IAF (Índice de Área Foliar) médio foi $1,2 \mathrm{~m}^{2} \mathrm{~m}^{-2}$, nas árvores jovens, e de 8,3 $\mathrm{m}^{2} \mathrm{~m}^{-2}$, nas árvores adultas. As relações entre áreas foliares e biomassas das partes aéreas com as áreas superficiais e biomassas de raízes finas e médias refletem os padrões de alocação de carbono nas árvores, até a idade em que foram avaliadas. A área foliar é um bom estimador da área superficial de raízes de teca.

Palavras-chave: Tectona grandis; raízes finas; área radicular; área foliar e biomassa.

\section{ABSTRACT}

\section{Above- and below-ground relationships in teak stands}

There is little information available about teak leaves and roots in Brazil. The objectives of this work were to evaluate if the above-ground components, biomass, and leaf area are good biomass and root surface estimators in teak (Tectona grandis) stands. In the sampling, executed in 17- and 90-month-old teak trees established in commercial stands, the roots, stem, branches, and leaves were separated to determine the dry biomass and specific leaf area (SLA) and specific root area (SRA). The leaf surface of a young tree was four times larger than the surface of an adult teak tree leaf. The fine roots surface $(<2 \mathrm{~mm})$ was four times larger than the medium roots surface $(2$ to $5 \mathrm{~mm})$ in adult trees. In these stands, on average, SLA was $13.14 \mathrm{~m}^{2} \mathrm{~kg}^{-1}$ and SRA was $13.86 \mathrm{~m}^{2} \mathrm{~kg}^{-1}$, indicating similar C use efficiency in the production of surfaces for acquisition of resources (solar radiation, water, and nutrients) and suggesting that there was synchrony in the $\mathrm{C}$ allocation for leaves and roots. The leaf area index was $1.2 \mathrm{~m}^{2} \mathrm{~m}^{-2}$ in the young plants and 8.3 $\mathrm{m}^{2} \mathrm{~m}^{-2}$ in the adult plants. Leaf area and above-ground biomass have strong relationship with fine and middle roots area and root biomass, reflecting the carbon allocation patterns of trees at the age that they were assessed. Leaf area is a good estimator of the surface area of teak roots.

Key words: Tectona grandis; fine roots; roots area; leaf area; biomas.

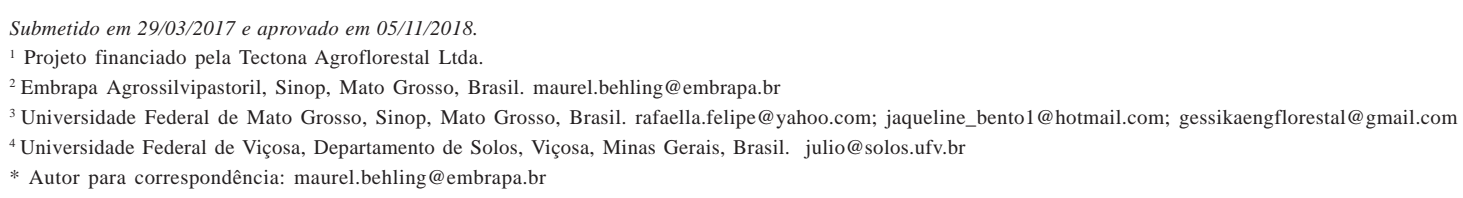




\section{INTRODUÇÃO}

$\mathrm{O}$ aumento dos plantios de teca (Tectona grandis) no Estado de Mato Grosso deve-se, em parte, às condições edafoclimáticas favoráveis da região. Apesar disso, é necessário conhecer as relações entre a água, o solo, a planta e a atmosfera para a obtenção de produtividades economicamente rentáveis que atendam às exigências dos mercados internos e externos. Nessas relações, é de grande importância a obtenção de informações complementares referentes ao desenvolvimento do sistema radicular da teca (Behling et al., 2014).

A taxa fotossintética por unidade de área foliar é modulada pelo sistema radicular. No entanto, são complexas as relações entre os dois principais compartimentos da planta (parte aérea e sistema radicular) e o solo, sendo este considerado mais do que um simples substrato para a fixação das plantas e, o sistema radicular, mais do que um órgão especializado na absorção de água e nutrientes. Ambos devem ser vistos como meios naturais, complexos e dinâmicos, que interagem e influenciam-se mutuamente, pois a planta, por meio de seu sistema radicular, promove mudanças químicas, físicas e biológicas no solo, que também ocasionam mudanças no desenvolvimento do sistema radicular e da parte aérea das plantas (Maurice et al., 2010; Laclau et al., 2013; Hajek et al., 2013; Noguchi et al., 2013; Rosenvald et al., 2013 e Pinheiro et al., 2016).

O maior crescimento do sítio florestal depende da rápida e eficiente aquisição de recursos acima e abaixo do solo e, portanto, as árvores de maior crescimento geralmente apresentam maiores área radicular específica (ARE) e área foliar específica (AFE) e, também, uma correlação positiva entre o índice de área radicular (IAR) e índice de área foliar (IAF) (Al Afas et al., 2008; Reich, 2014; Jo et al., 2015). Na predição do crescimento do sítio florestal, há que se lidar com a complexidade dos processos fisiológicos envolvidos na alocação de carbono (C) para os componentes das árvores, principalmente na formação de folhas e de raízes finas (diâmetro $<2 \mathrm{~mm}$ ), as superfícies de aquisição dos recursos radiação solar, água e nutrientes minerais, respectivamente (Campoe et al., 2012; Laclau et al., 2013; Pinheiro et al., 2016).

Existe pouca informação sobre o desenvolvimento do sistema radicular da teca, em plantios comerciais, no Estado de Mato Grosso. A grande maioria dos estudos realizados nesse compartimento da árvore trata apenas do sistema radicular de sustentação, constituído pelas raízes mais grossas. Esta limitação está relacionada, principalmente, com a complexidade de estudos dessa natureza, que envolvem grande demanda de tempo, de mão de obra e custo elevado (Behling et al., 2014). Assim, o ajuste de equações alométricas, associando raízes com parte aérea, para a predição da biomassa e da área radicular torna-se im- portante recurso para simplificar o processo de obtenção dessas variáveis com menor custo. Este estudo teve por objetivo, portanto, avaliar se os componentes da parte aérea, biomassa e área de folhas, são bons estimadores da biomassa e da superfície de raízes em povoamentos de teca.

\section{MATERIAL E MÉTODOS}

O estudo foi desenvolvido com dados obtidos no município de Tangará da Serra, MT em plantios da empresa Tectona Agroflorestal-LTDA, localizada a $14^{\circ} 04^{\prime} 38^{\prime \prime} \mathrm{S}$ e $57^{\circ} 03^{\prime} 45^{\prime \prime} \mathrm{O}$, com altitude média de $387 \mathrm{~m}$. O clima é do tipo Aw tropical, quente e subúmido, conforme a classificação de Köppen, com quatro meses secos, de junho a setembro. A precipitação pluviométrica anual é de 1.750 $\mathrm{mm}$, sendo janeiro, fevereiro e março os meses mais chuvosos. A temperatura média anual é de $24^{\circ} \mathrm{C}$ (Alvares et al., 2013). Aárea apresenta topografia suave ondulada e a classe de solo predominante é o Argissolo Vermelho. A vegetação é composta de mata de transição entre floresta amazônica e cerrado.

$\mathrm{Na}$ área de estudo, foram distribuídas, aleatoriamente, cinco parcelas com 132 árvores adultas cada uma (950,4 $\mathrm{m}^{2}$ ), espaçamento inicial de 3 x 2,4 m, plantadas nos meses de outubro a dezembro de 1998 (90 meses) e duas parcelas jovens com 132 árvores cada uma $\left(1188 \mathrm{~m}^{2}\right)$, espaçamento inicial de $3 \times 3 \mathrm{~m}$, em plantios realizados no mês de dezembro de 2004 (17 meses).

A seleção das árvores para abate e quantificação de raízes e folhas foi realizada conforme Behling et al. (2014). À medida que as árvores foram derrubadas, os galhos eram separados do tronco e deles foram coletadas todas as folhas. Todos os componentes tiveram sua massa fresca determinada ainda no campo, com uma balança com capacidade de pesar até $250 \mathrm{~kg}$. Os troncos, divididos em toretes, foram separados em casca e lenho, sendo também pesados individualmente. Amostras foram retiradas de cada um dos componentes (folhas, galhos, casca e lenho), as quais foram pesadas no campo com balança de precisão. Posteriormente, as amostras foram secadas em estufa, a $75^{\circ} \mathrm{C}$, até peso constante ( \pm 96 horas) e depois pesadas (Behling et al., 2014). Por meio dos valores de umidade e do peso de matéria fresca das amostras de todos os componentes das árvores, foram obtidos os valores das biomassas secas por árvore.

A determinação da área foliar foi feita mediante a coleta de seis a oito folhas, em cada árvore abatida, por classe de diâmetro. Posteriormente, a área individual de cada folha foi medida com o integrador eletrônico de área foliar da marca LiCor, Mod. LI-3100, seguindo-se a secagem em estufa para obtenção da matéria seca. A área foliar foi dividida pela matéria seca da amostra, obtendo-se, assim, 
a área foliar específica (AFE) em $\mathrm{m}^{2} \mathrm{~kg}^{-1}$ de matéria seca de folhas. $\mathrm{O}$ valor da AFE, juntamente com o peso de matéria seca total de folhas de cada árvore e a respectiva área útil permitiram o cálculo da área de folhas $\left(\mathrm{m}^{2}\right)$ por área de solo $\left(\mathrm{m}^{2}\right)$, ou seja, o índice de área foliar $\left(\mathrm{IAF}, \mathrm{m}^{2} \mathrm{~m}^{-2}\right)$.

A determinação da distribuição das raízes e de suas biomassas foi realizada na árvore média de três parcelas com árvores adultas, conforme Behling et al. (2014). As amostras das diferentes classes de diâmetro $(\Phi)$ de raízes, grossas (> $5 \mathrm{~mm} \Phi)$, médias ( 2 a $5 \mathrm{~mm} \Phi)$ e finas (<2 $\mathrm{mm} \Phi)$ foram secadas em estufa, a $75^{\circ} \mathrm{C}$, até peso constante $( \pm 96$ horas) e depois pesadas. Com os valores de umidade e de pesos de matéria fresca das amostras, foram obtidos os valores das biomassas secas por árvore. Por meio das relações entre biomassas de raízes grossas, médias e finas com a biomassa da parte aérea foi estimada a biomassa total de raízes para as demais árvores avaliadas.

Subamostras das raízes médias e finas $( \pm 0,5 \mathrm{~g})$ foram digitalizadas na resolução de 100 dpi e 200 dpi, respectivamente, em scanner HP Scanjet ${ }^{\circledR}$ 8200. O programa QuantRoot $^{\circledR}$ foi utilizado para o processamento das imagens e geração dos atributos morfométricos área e comprimento, com posterior cálculo do comprimento total e da superfície radicular.

Após a digitalização, as subamostras de raízes foram secadas em estufa de circulação e renovação de ar, a $75^{\circ} \mathrm{C}$, até peso constante, e pesadas em balança com $0,001 \mathrm{~g}$ de precisão. A área radicular foi dividida pela matéria seca da amostra, obtendo-se assim a área radicular específica (ARE), em m $\mathrm{kg}^{-1}$ de matérias secas de raízes finas e médias. O valor da ARE, juntamente com os das respectivas matéria seca de raízes finas e médias de cada árvore e a respectiva área útil permitiram o cálculo da área da superfície de raízes $\left(\mathrm{m}^{2}\right)$ por área de solo $\left(\mathrm{m}^{2}\right)$, ou seja, o índice de área radicular (IAR $\mathrm{m}^{2} \mathrm{~m}^{-2}$ ) para raízes finas e médias (Behling et al., 2014).

Foi realizada a análise de variância para se verificar o efeito da idade e das classes de diâmetro. Posteriormente, os dados foram submetidos à análise de regressão e os critérios utilizados para a escolha do melhor modelo foram a análise do coeficiente de determinação $\left(\mathrm{R}^{2}\right)$ ou do coeficiente de correlação $\left(r_{w y}\right)$ e a distribuição dos dados observados em torno das regressões ajustadas.

\section{RESULTADOS E DISCUSSÃO}

As áreas foliares individuais de teca diferiram ( $\mathrm{p}<$ 0,05) entre árvores jovens e adultas, ou seja, as árvores jovens apresentam área foliar maior, de aproximadamente quatro vezes a das árvores adultas. Nas árvores adultas, não se observaram diferenças significativas $(p>0,05)$ das áreas foliares individuais das folhas entre as classes de DAP (Figura 1a). Nos indivíduos adultos, as folhas apre- sentaram, em média, de 30 a $40 \mathrm{~cm}$ de comprimento por 25 $\mathrm{cm}$ de largura, enquanto, nas árvores mais jovens, de até três anos de idade, as folhas podem atingir o dobro dessas dimensões.

Não se observaram diferenças significativas ( $\mathrm{p}>0,05)$ nos valores de áreas foliares específicas entre as classes de diâmetro aos 90 meses, mas eles diferiram daqueles das árvores com 17 meses ( $\mathrm{p}<0,001)$. A área foliar específica das árvores adultas foi $54 \%$ superior à das árvores jovens (Figura 1b). O inverso da área foliar específica reflete a espessura da folha, sendo o comportamento morfológico e anatômico da razão de área foliar (RAF), relacionando a superfície com o peso da matéria seca da própria folha. Assim, no início do desenvolvimento, os valores da AFE são maiores, com folhas pouco finas, pobres em matéria seca e com baixos valores de área foliar, o que na verdade não se obteve para teca, sendo as folhas jovens maiores e mais espessas, porém com AFE menor (Figura 1a e 1b). Portanto, na teca ocorre relação inversa entre a AF e AFE com o crescimento das árvores.

Esses resultados estão diretamente relacionados com as reduções da área foliar e da matéria seca de folhas que ocorrem durante o desenvolvimento da teca. Com o avanço da idade, as árvores de um povoamento alocam, proporcionalmente, menos biomassa para as folhas e mais para o tronco. Possivelmente, a redução da área foliar, geneticamente condicionada, seja inferior ao acúmulo de matéria seca nas próprias folhas, formando órgãos com menos reservas e, portanto, folhas menos espessas à medida que a planta se desenvolve, pelo menos até aos 90 meses de idade. Este fato é corroborado pela área individual das folhas, maior nas árvores jovens, diminuindo com o avanço da idade, ou seja, uma redução da área foliar individual de aproximadamente $73 \%$, das árvores adultas, em relação à das árvores jovens (Figura 1a).

Esta redução do tamanho das folhas de teca, além de estar associada com alocação de C, certamente está associada com a relação entre a largura de uma determinada folha e a distância vertical desta até o ponto inferior de recepção de luz, ou seja, com o padrão de distribuição vertical entre folhas para permitir a passagem de luz dentro da copa. Reduzindo-se os valores da área foliar individual, obtêm-se aumentos significativos de penetração de luz no dossel. Assim, a eficiência do crescimento pode estar relacionada com a habilidade de adaptação da planta às condições de intensidade luminosa do ambiente, estando os efeitos mais significativos da intensidade de luz relacionados com os aspectos qualitativos (Campoe etal., 2013).

Assim, a maior AFE das plantas adultas de teca também pode ser uma resposta adaptativa ao seu regime de desfolhação (espécie caducifólia). Após uma desfolhação severa da copa, no início da estação seca, a dinâmica de 
restauração da capacidade para absorção de luz e, portanto, do suprimento de $\mathrm{C}$ depende, diretamente, da dinâmica de expansão da área foliar no início do período chuvoso. Assim, as plantas que têm maior taxa de alocação de $\mathrm{C}$ nos meristemas foliares (alta relação entre parte aé-

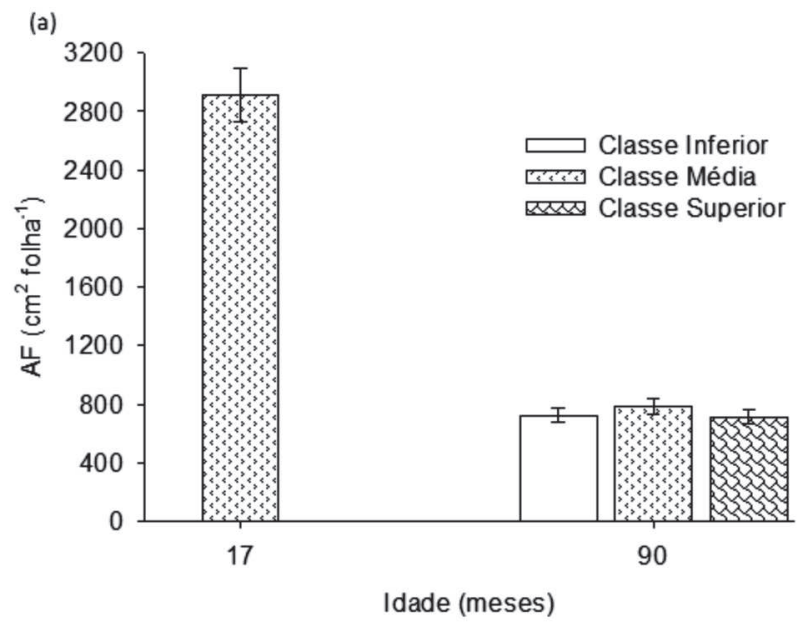

(b)

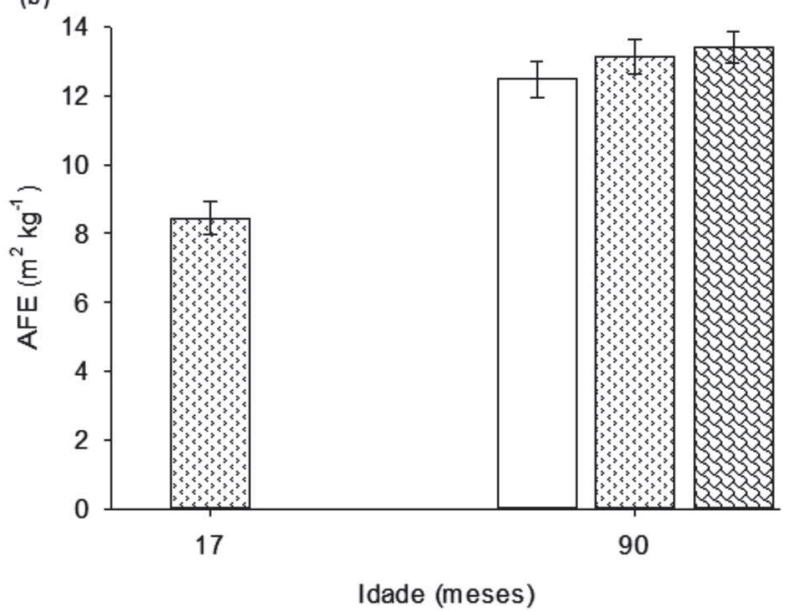

(d)

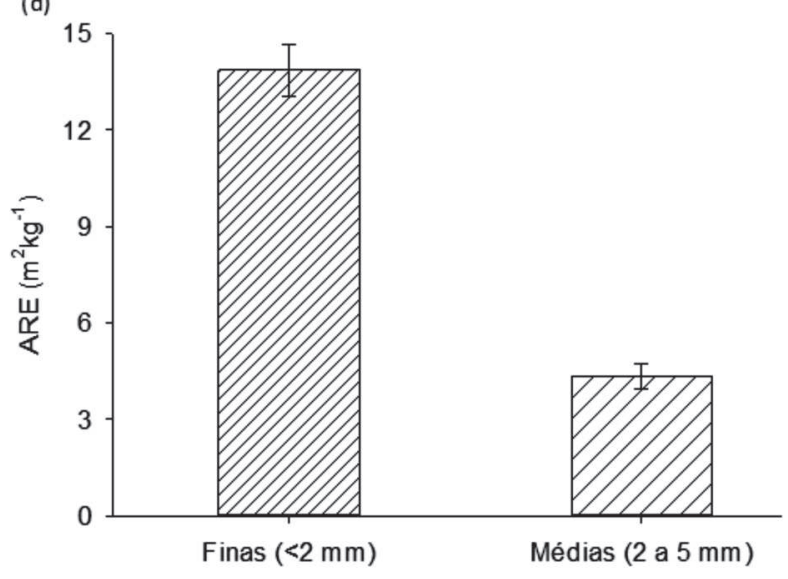

Classes de raízes

(c) rea e raiz), associada com maior área foliar específica (AFE), que corresponde à alta razão de área foliar (RAF, em m² de área foliar por g de massa da planta), pode ter maior taxa de crescimento após a desfolhação do que plantas com baixa RAF.
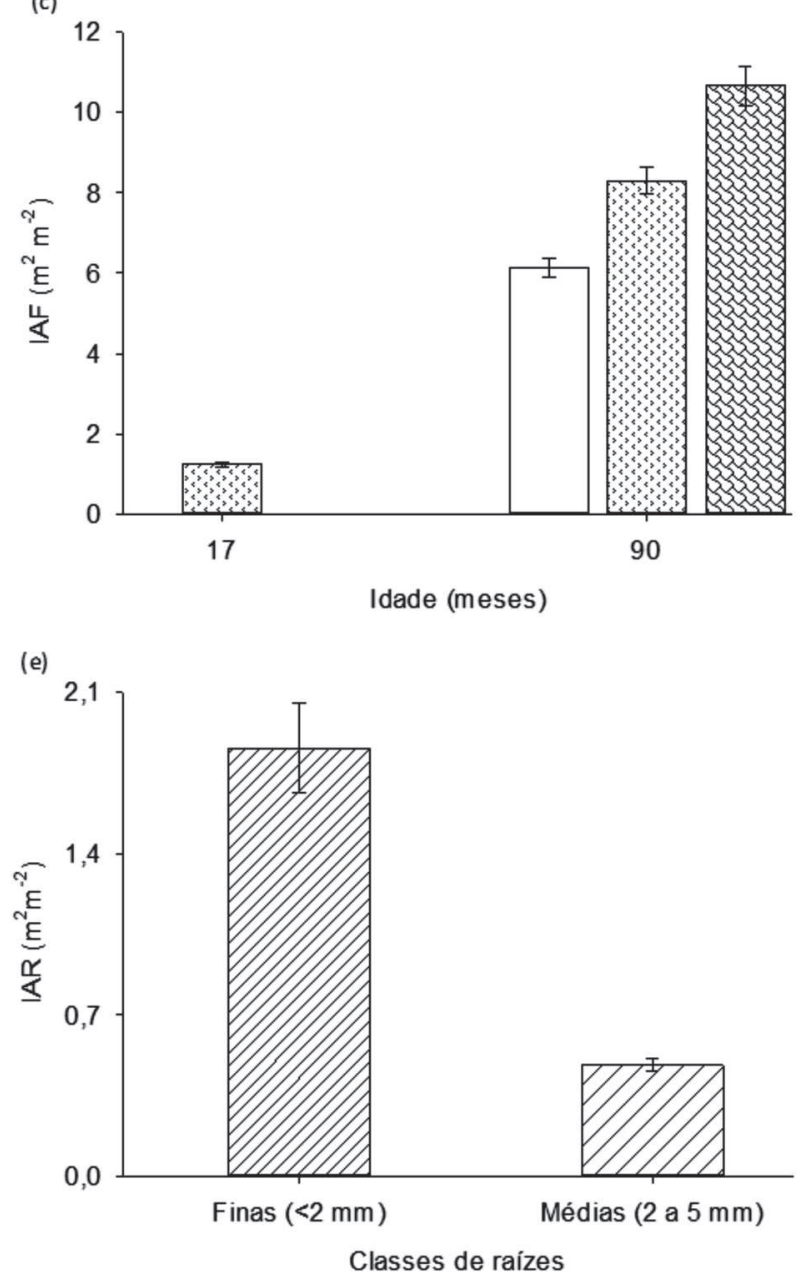

Barras verticais em cada coluna representam o erro padrão da média.

Figura 1. (a) Área foliar individual (AF), (b) área foliar específica (AFE) e (c) índice de área foliar (IAF) em plantios de teca com 17 e 90 meses nas diferentes classes de diâmetro e (d) área radicular específica (ARE) e (e) índice de área radicular (IAR) em raízes finas e médias de árvores de teca. 
Consequentemente, os valores de IAF diferiram entre árvores jovens (17 meses) e as árvores adultas (90 meses) $(\mathrm{p} \leq 0,001)$. As árvores jovens apresentaram um IAF médio de $1,2 \mathrm{~m}^{2} \mathrm{~m}^{-2}$. Nas árvores adultas, esse parâmetro variou entre 4,9 e 14,3 $\mathrm{m}^{2} \mathrm{~m}^{-2}$, com diferenças significativas $(\mathrm{p} \leq 0,001)$ entre as classes de diâmetros (Figura 1c). O índice de área foliar varia conforme o povoamento, sendo inferior a 1 em reflorestamentos novos, podendo alcançar valores acima de $8 \mathrm{~m}^{2} \mathrm{~m}^{-2}$. O IAF e a duração da área foliar são os fatores mais importantes na determinação de maté- ria seca e, consequentemente, do crescimento (Peixoto et al., 2011).

Valores máximos de IAF de várias culturas geralmente estão entre 8 a $12 \mathrm{~m}^{2} \mathrm{~m}^{-2}$ (Waring et al., 2014), variando conforme a espécie e a densidade de plantio. Entretanto, o ideal seriam valores que permitam uma ótima fotossíntese líquida, ou seja, um IAF no qual as folhas interceptam cerca de $95 \%$ da incidência de radiação solar, refletindo em um maior acúmulo de biomassa pelas árvores. A interceptação de radiação solar aumenta, ainda que de

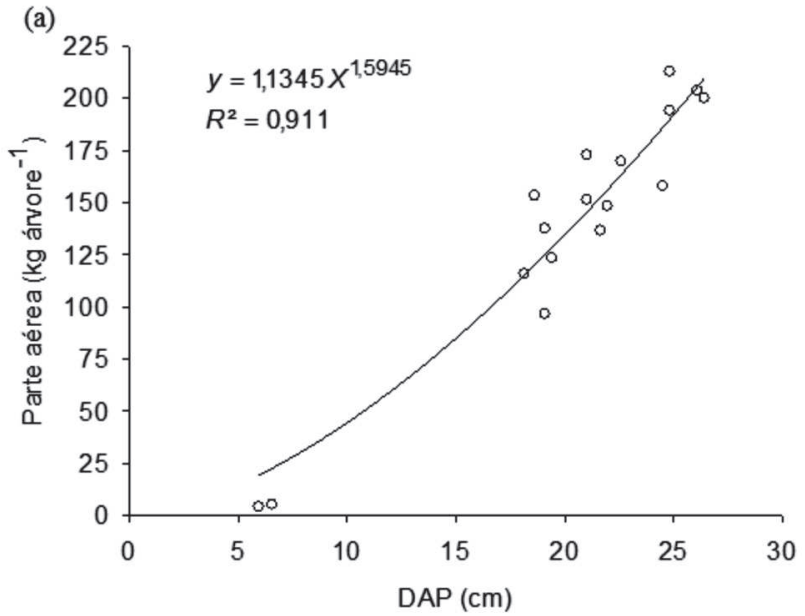

(b)

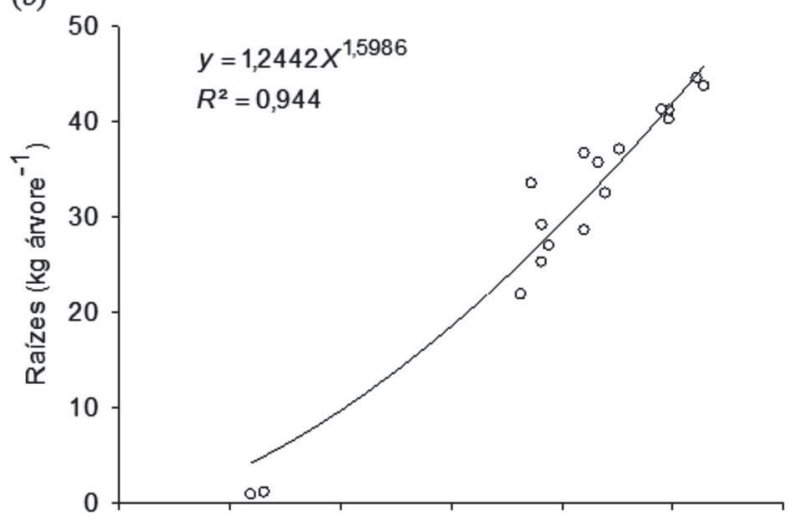

(d)

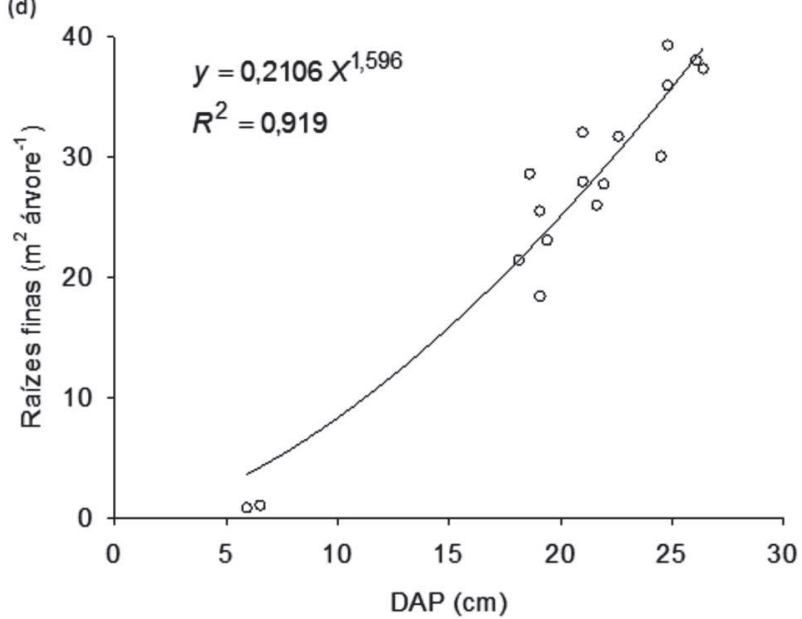

(c)

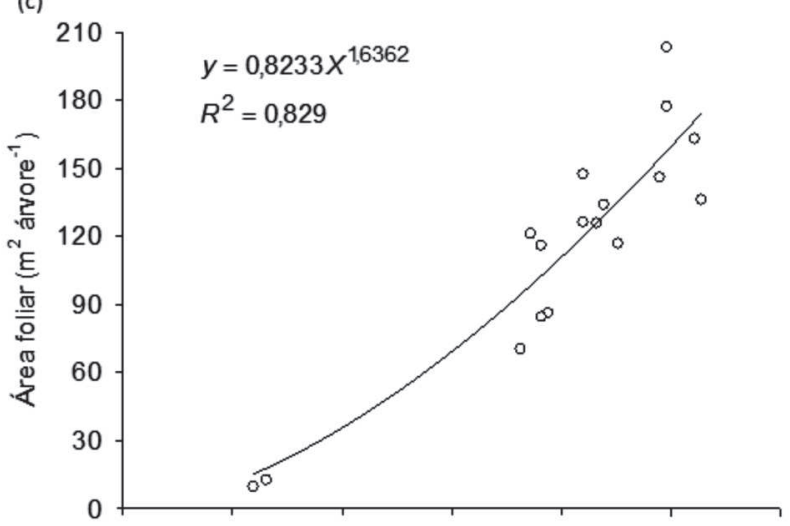

(e)

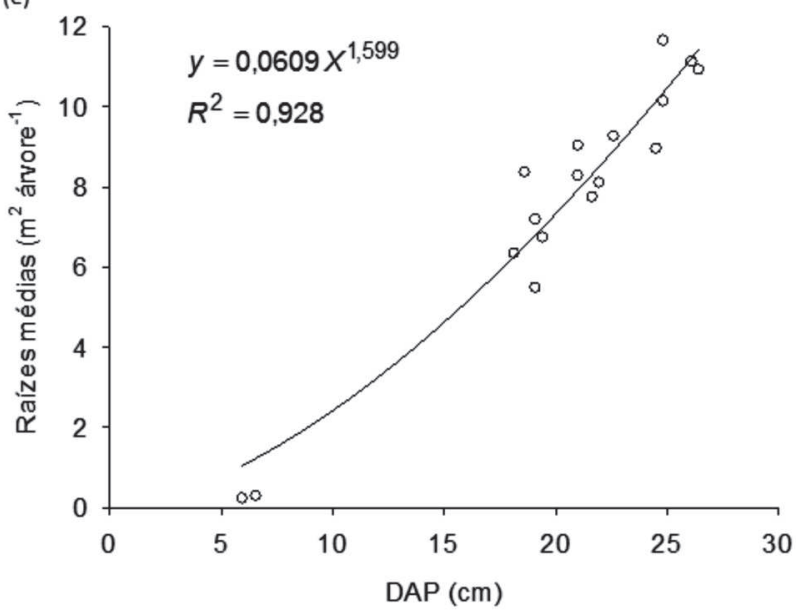

Figura 2. Relações alométricas entre biomassas da parte aérea (a) e de raízes (b), área foliar (c) e áreas radiculares de raízes finas (d) e médias (e) com o diâmetro à altura do peito (DAP) de árvores de teca. 
modo curvilíneo, mediante curva tendendo à saturação, com o aumento do IAF, relacionamento este que pode ser descrito pela lei de Beer e é largamente utilizado em modelos baseados em processos (MBP), como, por exemplo, o 3-PG (Waring et al., 2014).

Utilizando-se da lei de Beer, vê-se que, para valores de IAF superiores a $4,5-5 \mathrm{~m}^{2} \mathrm{~m}^{-2}$, não mais ocorrem aumentos importantes da interceptação de radiação solar. Neste trabalho, portanto, os elevados valores de IAF, obtidos para as árvores adultas (Figura 1c), não mais estariam contribuindo para ganhos adicionais importantes na interceptação de radiação solar. Os maiores valores de crescimento, observados para a classe de diâmetro superior, não devem ser consequência apenas de uma maior expansão da superfície fotossintetizante (> IAF), mas de toda a dinâmica de desenvolvimento do povoamento, resultando em árvores com diferentes classes de copa, alocadas na categoria das suprimidas e outras, de maior tamanho e vigor, na categoria de copas codominantes e dominantes.

As raízes finas e médias praticamente não diferiram em termos de produção de biomassa radicular, apresentando $1335( \pm 101)$ e $1258( \pm 139) \mathrm{kg} \mathrm{ha}^{-1}$ para raízes finas e médias, respectivamente, embora, quando analisadas, as diferenças sejam marcantes para as características que relacionam superfícies e comprimentos radiculares. As superfície radiculares apresentaram valores médios de $18.441 \mathrm{~m}^{2}$ $\mathrm{ha}^{-1}$, para raízes finas, e de $4.813 \mathrm{~m}^{2} \mathrm{ha}^{-1}$, para as raízes médias. O comprimento médio de raízes finas, no perfil de $60 \mathrm{~cm}$ do solo, foi de $8.237 \mathrm{~km} \mathrm{ha}^{-1}$, contra apenas $522 \mathrm{~km}$ ha $^{-1}$, para as raízes médias, numa razão de 16:1, ou seja, para cada metro de raízes médias, há aproximadamente 16 metros de raízes finas (Behling et al., 2014).

As áreas radiculares específicas de raízes finas e médias de teca diferiram, ou seja, as raízes finas apresentam ARE 3,2 vezes maior que as raízes médias (Figura 1d). Analogamente ao raciocínio para folhas, pode-se dizer que uma maior área radicular específica (ARE), que corresponde à alta razão de área radicular (RAR em m² de área radicular por g de massa da planta), representa uma maior taxa de crescimento e de renovação, refletindo-se na maior dinâmica das raízes finas, em comparação com a das médias. A rápida regeneração das raízes pode ser vantajosa em ambientes ricos em nutrientes, nos quais a eficiência na captura de recursos é provavelmente maximizada pela redução da longevidade das raízes, aumentando a capacidade de absorção e reduzindo os custos de manutenção (Laclau et al., 2013; Pinheiro et al., 2016).

Independentemente do sítio e das espécies, árvores jovens necessitam produzir seu sistema radicular rapidamente (Rosenvald et al., 2013). Portanto, raízes finas de árvores de teca são pequenas em diâmetro, porém com elevada ARE (Figura 1d). Logo, a ARE diminui de forma logarítmica com a idade do povoamento e a idade das raízes, de maneira similar às características da vida útil das folhas (Maurice et al., 2010; Hajek et al., 2013; Noguchi et al., 2013 e Rosenvald et al., 2013).

Os índices de área de superfície radicular (IAR) foram cerca de quatro vezes maiores nas raízes finas do que nas raízes médias (Figura 1e). Considerando-se todas as raízes menores que $5 \mathrm{~mm}$, o IAR de 2,34 $\mathrm{m}^{2} \mathrm{~m}^{-2}$, as raízes finas (< $2 \mathrm{~mm}$ ) correspondem a $80 \%$ do valor total do IAR.

No entanto, os valores de IAR obtidos para teca estão abaixo da faixa de 4,6 a 79,11 $\mathrm{m}^{2} \mathrm{~m}^{-2}$, encontrados em dez diferentes biomas estudados por Jackson et al. (1997). Em estudo com 16 diferentes materiais genéticos do gênero Eucalyptus, houve uma variação entre os materiais, sendo o menor índice médio de $4,9 \mathrm{~m}^{2} \mathrm{~m}^{-2}$ e o maior de 9,3 $\mathrm{m}^{2} \mathrm{~m}^{-2}$, para raízes finas $<2 \mathrm{~mm}$ (Pinheiro et al., 2016). No entanto, esses valores não podem ser comparados diretamente, dadas as diferenças intrínsecas de cada espécie, as condições edáficas e os diferentes métodos de coleta e de medida da superfície radicular.

Fazendo-se comparações entre os comprimentos de raízes e as áreas radiculares, têm-se $823,7 \mathrm{~m}$ de raízes por metro quadrado de solo e $446 \mathrm{~m}$ de raízes por metro quadrado de superfície radicular para raízes finas, enquanto, para raízes médias, esses valores foram modestos, com $52,2 \mathrm{~m}$ de raízes por metro quadrado de solo e $109 \mathrm{~m}$ de raízes por metro quadrado de superfície radicular. Esses valores, apesar de relacionados com uma área plana, representam uma maior capacidade das raízes finas para explorar determinado volume de solo, ou seja, essas relações de comprimento estão contempladas no IAR.

As relações entre áreas foliares e biomassas de partes aéreas e de raízes finas são consistentes. Quando examinado o conjunto dos dados, há várias relações significativas entre os componentes de parte aérea e de raízes, considerando-se a árvore individual (Figuras 2 a 4). Em particular, este estudo demonstrou relações lineares e não lineares consistentes entre produção (biomassa de folhas e raízes) e captura de recursos (área de folhas e área superficial de raízes).

O diâmetro à altura do peito (DAP, $\mathrm{cm}$ ) foi uma variável explicativa importante para biomassa de parte aérea $\left(\mathrm{kg}\right.$ árvore $\left.^{-1}\right)$ e da biomassa total de raízes ( $\mathrm{kg}$ árvore $\left.{ }^{-1}\right)$. Por meio dessas relações alométricas (Figura 2), é possível estimar a biomassa e a área superficial de raízes em povoamentos de teca, embora, há de se considerar a dinâmica das raízes finas impactando significativamente os ciclos de carbono, em escala de árvore individual e de povoamento, pois apresentam elevada contribuição para a imobilização de C. As raízes finas menores que $2 \mathrm{~mm}$ contribuem com 25 a $80 \%$ do acúmulo total de carbono, anualmente, no solo (Freitas et al., 2008; Laclau et al., 2013; Pinheiro et al., 2016). 
A teca apresentou, em média, AFE de $13,01 \mathrm{~m}^{2} \mathrm{~kg}^{-1} \mathrm{e}$ ARE de 13,86 $\mathrm{m}^{2} \mathrm{~kg}^{-1}$, indicando eficiência semelhante quanto à utilização do $\mathrm{C}$, na produção de superfícies para aquisição dos recursos radiação solar, água e nutrientes e, ainda, que há sincronia na alocação de $\mathrm{C}$ entre folhas e raízes finas, para formação de novos tecidos foliares e radiculares. Essas relações refletem os padrões de alocação de carbono nas árvores, até a idade em que fo- ram medidas, e são úteis em MBP, ao simplificarem o tratamento dos processos fisiológicos envolvidos (Figura 3a).

A relação obtida para a regressão entre AFE e ARE, com $\mathrm{R}^{2}$ de 0,744 , indica que a área foliar específica pode ser um bom estimador da área radicular específica e, indiretamente, da biomassa de raízes (Figura 3a). Essa relação fornece suporte para o balanço funcional entre as produções da parte aérea e a das raízes (Magnani et al., 2002). A

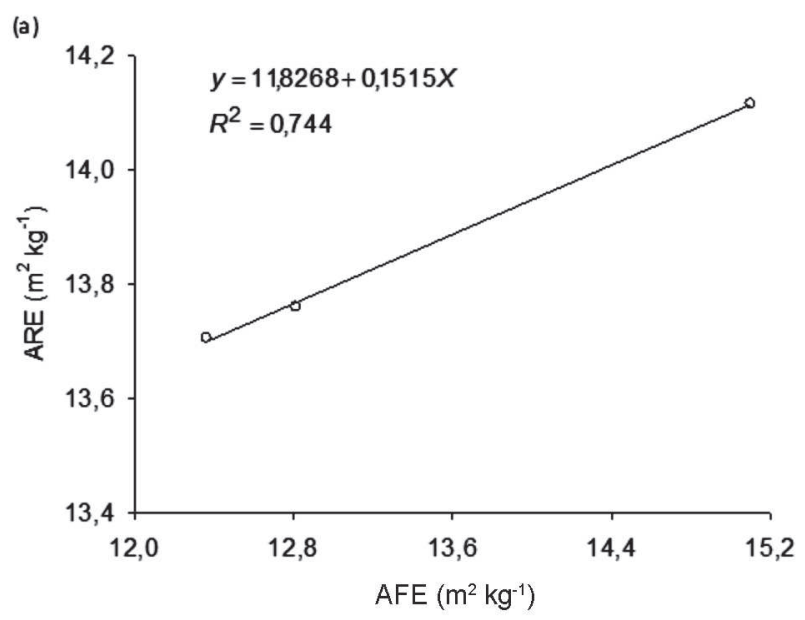

(b)

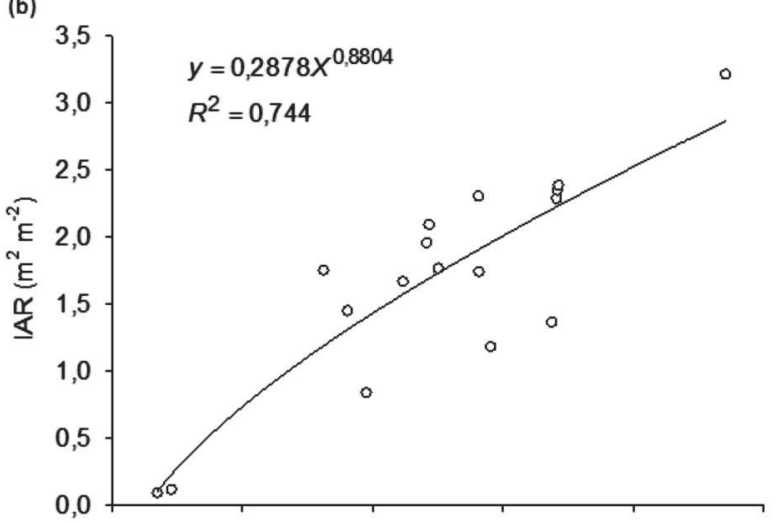

(c)

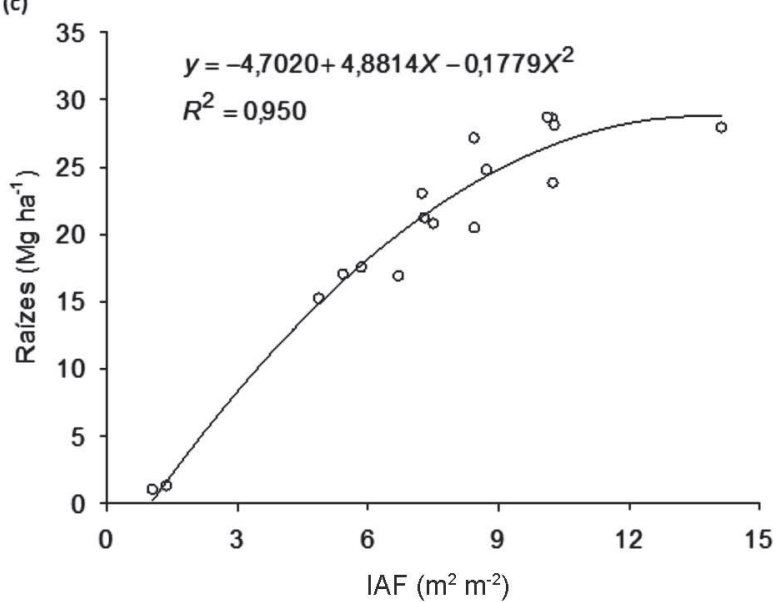

(d)

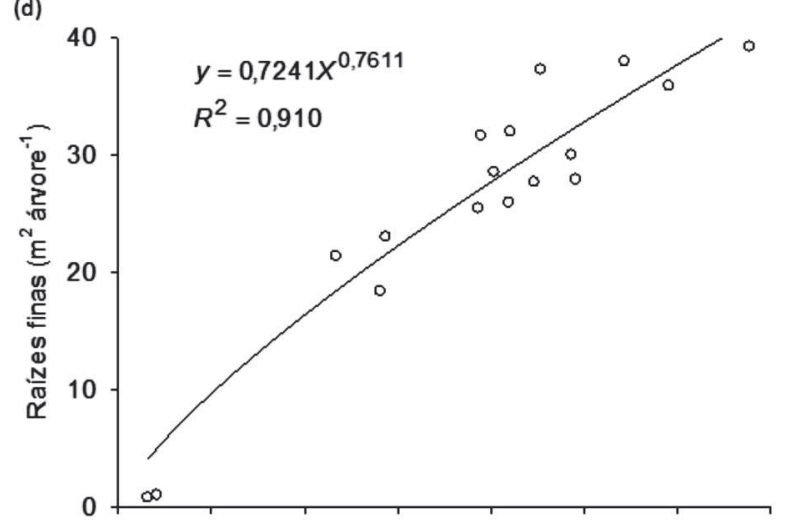

(e)

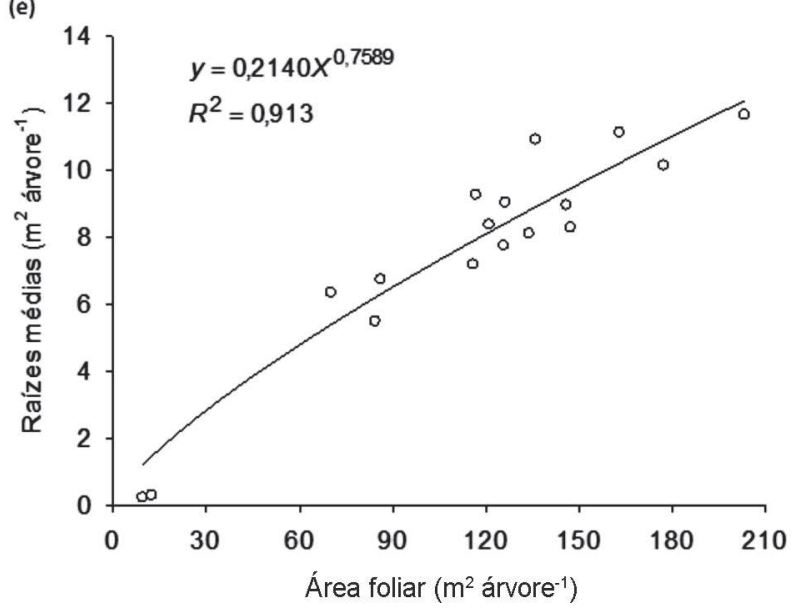

Figura 3. Relações entre a área radicular específica (ARE) e área foliar específica (AFE) (a), do índice de área radicular (IAR) (b) e biomassa de raízes secas (c) com o índice de área foliar (IAF), entre superfície de raízes finas (d) e médias (e) com área foliar de árvores de teca. 
relação curvilinear entre áreas de folhas e de raízes finas, encontrada em plantios de Eucalyptos globulus, no sul da Tasmânia, sugere mudanças no padrão de suprimento e de demanda de carbono com aumento da área foliar por unidade de área radicular com a idade (O'Grady et al., 2006). Embora, a proporção entre área de folhas e raízes precise manter-se constante para o suprimento de recursos à árvore (Tyree et al., 1998). A AFE apresenta melhor relação com a ARE que o comprimento radicular específico (CRE). As conclusões atuais sobre a relação AFE-CRE são controversas. Por exemplo, a relação AFE-CRE variou de positiva (Withington et al. 2006; Liu et al. 2010), a positiva/negativa, dependendo da escala (Kembel \& Cahill 2011; Geng et al. 2014) e sem relação significativa (Chen et al., 2013). Assim, estudos futuros são necessários para quantificar as mudanças nas relações entre área de folhas e superfície de raízes de teca durante o fechamento do dossel e sua potencial influência na condutância hidráulica de toda a planta e sua eficiência no uso da água, dos nutrientes e da luz.

Quando o índice de área foliar (IAF) e o índice de área radicular fina (IAR, estimado pela ARE média) foram expressos para uma área de $9 \mathrm{~m}^{2}$ árvore ${ }^{-1}$, para árvores jovens, e uma área média de $16 \mathrm{~m}^{2}$ árvore ${ }^{-1}$ (considerandose os desbastes), para as árvores adultas, o IAF explicou $74,4 \%$ da variação dos dados ocorrida no IAR (Figura 3b). Em um trabalho com cinco diferentes clones de Populus, na Bélgica, Al Afas et al. (2008) observaram que o IAF diferiu significativamente entre os clones, variando de 2,1 a $6,0 \mathrm{~m}^{2} \mathrm{~m}^{-2}$. O menor e o maior valores de IAR encontrados foram de 1,8 e $3,6 \mathrm{~m}^{2} \mathrm{~m}^{-2}$, respectivamente. Os autores encontraram uma correlação significativa e positiva entre o IAF e IAR, para todos os clones, em todas as profundidades estudadas, ou seja, o clone que apresentou o maior IAR também foi o que apresentou maior IAF.

Esse resultado é o oposto do encontrado no estudo realizado em Itatinga, SP, com 16 diferentes materiais genéticos do gênero Eucalyptus, indicando que a relação IAR/IAF pode variar de espécie para espécie e, ou, em função das condições ambientais e que a textura do solo pode ter influência sobre a área radicular e a área foliar de um mesmo material genético (Pinheiro et al., 2016).

A razão IAR/IAF mais elevada pode significar maior capacidade da árvore de suportar condições de déficit hídrico (Ng et al., 2016). Embora os pontos dos dados observados estejam bem abaixo da linha 1:1, isso sugere que um aumento relativamente grande do IAF de 1,0 para $14,1 \mathrm{~m}^{2} \mathrm{~m}^{-2}$ resultou em um pequeno aumento do IAR. Essa proporção IAR/IAF mais baixa pode indicar que houve uma ampla oferta de água no solo para as árvores crescerem, refletindo as condições do sítio com solo profundo.
Esse resultado indica que, ao se trabalhar com comunidade de árvores, as medidas de IAF podem ser usadas como estimadores de superfície e de biomassa radicular, com o IAF explicando $95 \%$ da variação da biomassa de raízes, por meio de modelo quadrático, com a máxima produção de raízes obtidas com um IAF de $13,7 \mathrm{~m}^{2} \mathrm{~m}^{-2}$ (Figura 3c). O melhor ajuste foi obtido com a característica do povoamento e não com a da árvore individual, dada a natureza do IAF. Entretanto, é necessário que o número de amostras seja ampliado e uma calibração dessa relação pode tornar a medida de IAF um estimador mais robusto para a da superfície de raízes.

Em particular, o estudo mostrou que a área foliar (AF) pode explicar $91 \%$ da área superficial de raízes finas e médias (Figura 3d e 3e), indicando mudanças no padrão de suprimento e na demanda da árvore com a idade, conforme constatado por O'Grady et al. (2006) em plantios de Eucalyptos globulus no sul da Tasmânia. Fatores como a relação fonte/dreno de carboidratos, distribuição de carbono entre as partes aérea e radicular e o ambiente da rizosfera afetam o crescimento das raízes e a sua senescência, como também o crescimento da parte aérea e a sua capacidade de fixação de carbono. O funcionamento de raízes é intenso quando a eficiência de absorção de água e de nutrientes por unidade de carbono é maximizada.

Quanto às características da árvore, a biomassa de folhas explicou $87,1 \%$ da variação da biomassa de raízes finas (Figura 4a) e 87,8\% da de raízes médias (Figura 4c). Já a biomassa da parte aérea explicou $88,6 \%$ da variação da biomassa de raízes finas (Figura 4b), 98,6\% da de raízes médias (Figura 4d) e 93,8\% da biomassa total de raízes (Figura 4f), enquanto a área foliar explica 91,5\% da biomassa total de raízes (Figura 4e). As raízes finas são importantes para aquisição de água e nutrientes e o equilíbrio funcional entre área foliar e o uso de água pressupõe, potencialmente, um equilíbrio funcional entre raízes finas e área foliar (Magnani et al. 2002).

A relação folhas/raízes finas (massa/massa) fornece uma indicação aproximada da relação fonte/dreno de fotoassimilados (Figura 4). Os conteúdos e a partição de $\mathrm{C}$, das folhas e das raízes finas, são os de menores valores entre os dos componentes dos plantios, sendo ainda muito próximos entre si. Esses dois componentes são os de maior atividade metabólica e representam as superfícies de aquisição de $\mathrm{C}$, água e nutrientes minerais. Na realidade, folhas e raízes finas têm altas taxas de renovação, o que faz com que suas biomassas e conteúdos de carbono, existentes num dado momento, possam não refletir a maior dinâmica desses componentes. Ou seja, a alocação de carbono para folhas e raízes finas seria muito maior do que a indicada por suas partições determinadas em avaliações pontuais. 
A relação da biomassa total de raízes com a área foliar teve um efeito quadrático e uma relação linear com a biomassa de parte aérea (Figura 4e e 4f). Comportamento semelhante foi observado por Misra et al. (1998), em Eucalyptus nitens com idade de 10 a 34 meses, em que se observou uma relação linear entre as biomassas de raízes
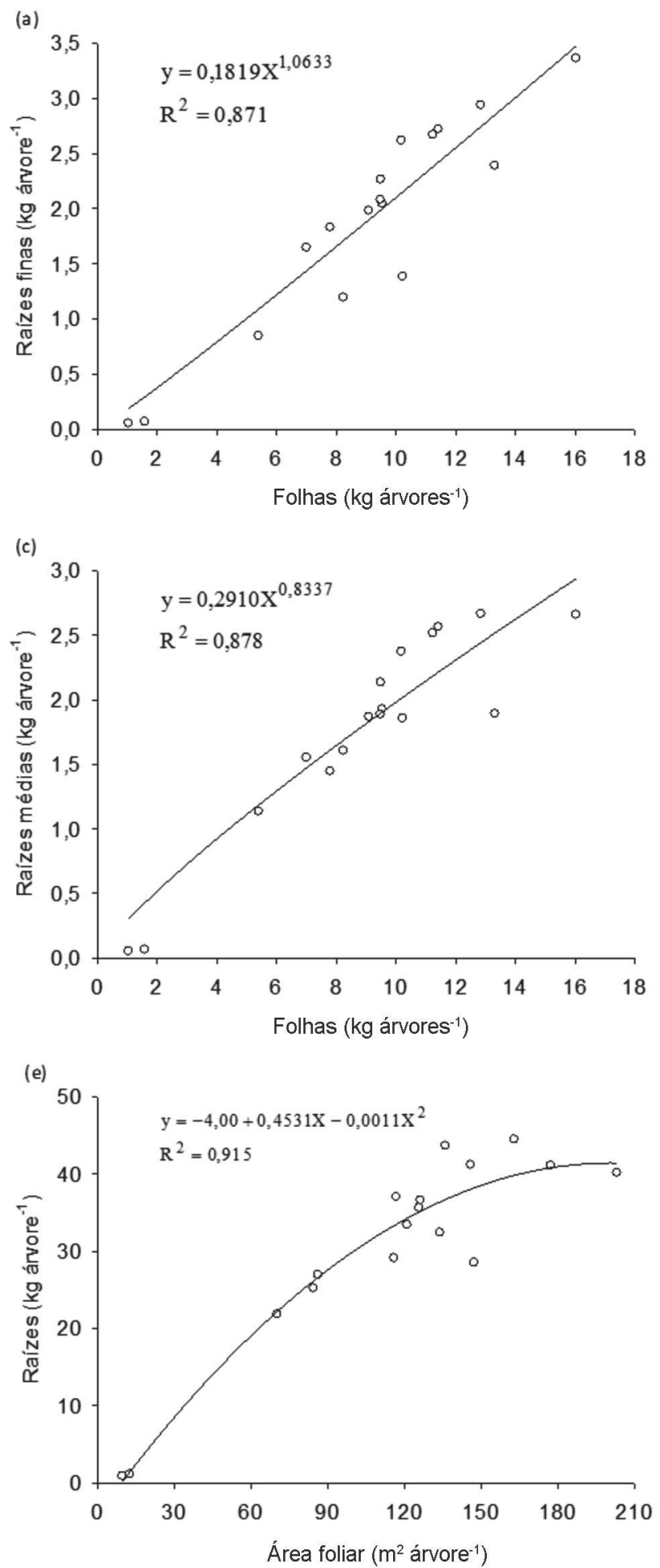

grossas e da parte aérea. Resh et al. (2003) também observaram uma relação linear entre biomassas de raízes grossas e da parte aérea, em árvores de E. Globulus com 12 anos de idade. Já O'Grady et al. (2006), estudando Eucalyptus globulus com idade variando de três a 14 meses, no sul da Tasmânia, observaram melhor ajuste para
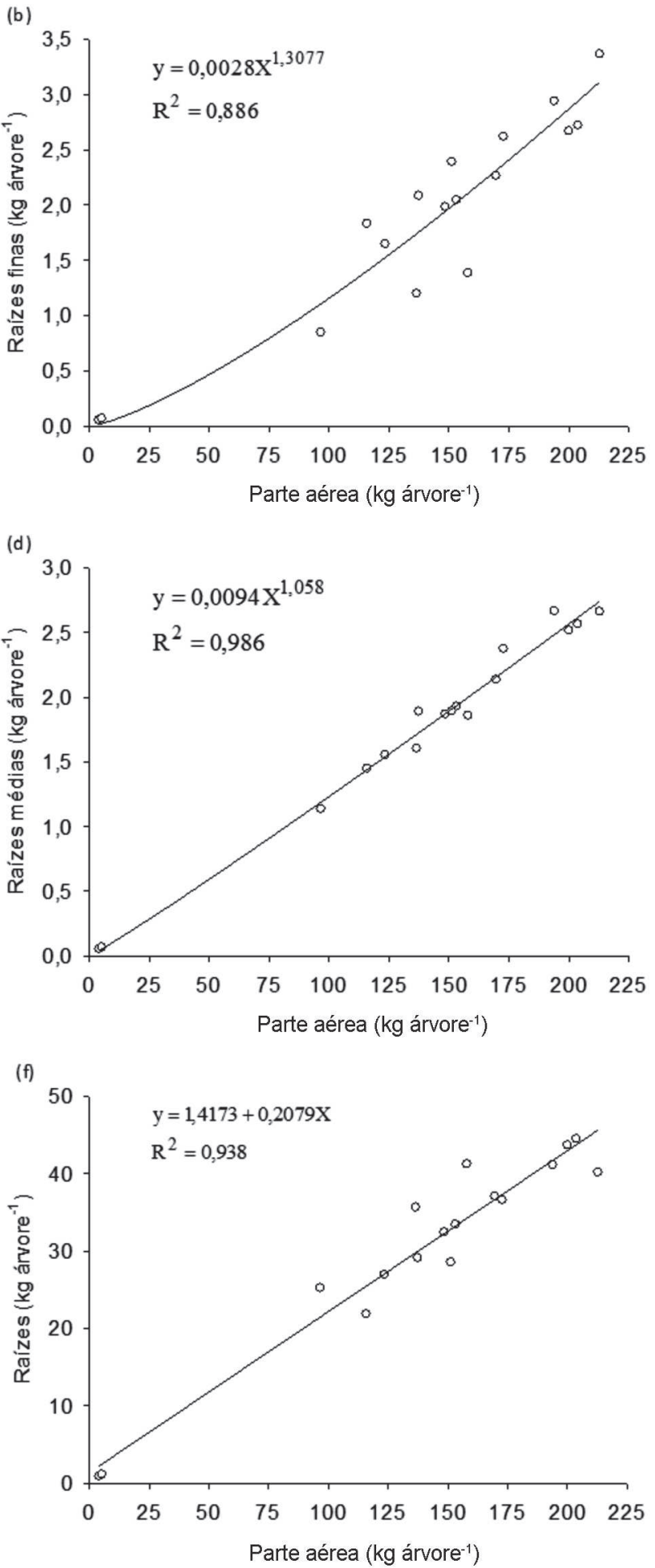

Figura 4. Relações entre biomassa de raízes finas com a biomassa de folhas (a) e biomassa da parte aérea (b), da biomassa de raízes médias com a biomassa de folhas (c) e biomassa da parte aérea (d), biomassa total de raízes com a área foliar (e) e biomassa total da parte aérea (f) de árvores de teca. 
a relação potencial entre biomassa de raízes grossas e biomassa da parte aérea e área foliar. Essas relações positivas entre biomassas e áreas de folhas com as biomassas e superfícies de raízes mostraram uma ligação intrínseca, representada na forma de função linear ou potencial, corroborada pela teoria do equilíbrio funcional entre os dois compartimentos (Meng et al., 2018; Jia et al., 2015 e O’Grady et al., 2006).

\section{CONCLUSÕES}

Há relações significativas, linear e potencial, entre a parte aérea e as raízes de teca.

A área foliar é um bom estimador da área superficial de raízes de teca.

As relações entre superfícies para aquisição dos recursos de radiação solar (folhas), água e nutrientes (raízes) refletem padrões semelhantes para alocação de carbono nas árvores, até a idade em que foram avaliadas.

\section{AGRADECIMENTOS}

Os autores agradecem ao CNPq, pela bolsa de pesquisa; e à Tectona Agroflorestal Ltda, pela disponibilidade da área e pelo financiamento do projeto.

\section{REFERÊNCIAS}

AL Afas N, Marron N, Zavalloni C \& Ceulemans R (2008) Growth and production of a short-rotation coppice culture of poplar IV: Fine root characteristics of five poplar clones. Biomass \& Bioenergy, 32:494-502.

Alvares CA, Stape JL, Sentelhas PC, Gonçalvez JLM \& Sparovek G (2013) Köppen's climate classification map for Brazil. Meteorologische Zeitschrift, 22:711-728.

Behling M, Neves JCL, Barros NF, Kishimoto CB \& Smit L (2014) Eficiência de utilização de nutrientes para formação de raízes finas e médias em povoamento de teca. Revista Árvore, 38:837846.

Campoe OC, Stape JL, Laclau JP, Marsden C \& Nouvellon Y (2012) Stand-level patterns of carbon fluxes and partitioning in a Eucalyptus grandis plantation across a gradient of productivity, in Sao Paulo State, Brazil. Tree Physiology, 32:696706 .

Campoe OC, Stape JL, Nouvellon Y, Laclau JP, Bauerle WL, Binkley D, Guerric LE \& Maire GL (2013) Stem production, light absorption and light use efficiency between dominant and nondominant trees of Eucalyptus grandis across a productivity gradient in Brazil. Forest Ecology and Management, 288:14-20.

Chen W, Zeng H, Eissenstat DM \& Guo D (2013) Variation of ûrst order root traits across climatic gradients and evolutionary trends in geological time. Global Ecology and Biogeography, 22:846856.

Freitas TAS, Barroso DG \& Carneiro JGA (2008) Dinâmica de raízes de espécies arbóreas: visão da literatura. Ciência Florestal, 18:133-142.

Geng Y, Wang L, Jin DM, Liu HY \& He JS (2014) Alpine climate alters the relationships between leaf and root morphological traits but not chemical traits. Oecologia, 175:445-455.
Hajek P, Hertel D \& Leuschner C (2013) Intraspecific variation in root and leaf traits and leaf-root trait linkages in eight aspen demes (Populus tremula and P. tremuloides). Frontiers in Plant Science, $4: 415$.

Jackson RB, Mooney HA \& Schulze ED (1997) A global budget for fine root biomass, surface area, and nutrient contents. Proceedings of the National Academy of Sciences USA, 94:73627366.

Jia Q, Liu Q \& Li J (2015) Individual-based fine root biomass and its functional relationship with leaf for Pinus tabuliformis in northern china. European Journal of Forest Research, 134:705714 .

Jo I, Fridley JD \& Frank DA (2015) Linking above-and belowground resource use strategies for native and invasive species of temperate deciduous forests. Biological Invasions, 17:15451554.

Kembel SW \& Cahill JF Jr (2011) Independent evolution of leaf and root traits within and among temperate grassland plant communities. Plos One, 6: e19992.

Laclau JP, Silva EA, Lambais GR, Bernoux M, Le Maire G, Stape JL, Bouillet JP, Gonçalves JLM, Jourdan C \& Nouvellon Y (2013) Dynamics of soil exploration by fine roots down to a depth of $10 \mathrm{~m}$ throughout the entire rotation in Eucalyptus grandis plantations. Frontiers in Plant Science, 4:01-12.

Liu G, Freschet GT, Pan X, Cornelissen JHC, Li Y \& Dong M (2010) Coordinated variation in leaf and root traits across multiple spatial scales in Chinese semi-arid and arid ecosystems. New Phytologist, 188:543-553.

Magnani F, Grace J \& Borghetti M (2002) Adjustment of tree structure in response to the environment under hydraulic constraints. Functional Ecology, 16:385-393.

Maurice J, Laclau JP, Scorzoni RED, Gonçalves JLM, Nouvellon Y, Bouillet JP, Stape JL, Ranger J, Behling M \& Chopart JL (2010) Fine root isotropy in Eucalyptus grandis plantations. Towards the prediction of root length densities from root counts on trench walls. Plant and Soil, 334:261-275.

Meng S, Jia Q, Zhou G, Zhou H, Liu Q \& Yu J (2018) Fine root biomass and its relationship with aboveground traits of Larix gmelinii trees in Northeastern China. Forests, 9:35.

Misra RK, Turnbull CRA, Cromer RN, Gibbons AK \& Lasala AV (1998) Below and above-ground growth of Eucalyptus nitens in a young plantation: I. Biomass. Foresty Ecology Management, 106:283-293.

Ng CWW, Garg A, Leung AK \& Hau BCH (2016) Relationships between leaf and root area indices and soil suction induced during drying-wetting cycles. Ecological Engineering, 91:113-118.

Noguchi K, Nagakura J \& Kaneko S (2013) Biomass and morphology of fine roots of sugi (Cryptomeria japonica) after 3 years of nitrogen fertilization. Frontiers in Plant Science, $4: 347$.

O'Grady AP, Worledge D \& Battaglia M (2006) Above-and belowground relationships, with particular reference to fine roots, in a young Eucalyptus globulus (Labill.) stand in southern Tamania. Trees, 20:531-538.

Peixoto CP, Cruz TV \& Peixoto MFS (2011) Análise quantitativa do crescimento de plantas: Conceitos e Prática. Enciclopédia Biosfera, 7:51-76.

Pinheiro RC, De Deus JC, Nouvellon Y, Campoe OC, Stape JL, Aló LL, Guerrini IA, Jourdan C \& Laclau JP (2016) A fast exploration of very deep soil layers by Eucalyptus seedlings and clones in Brazil. Forest Ecology and Management, 366:143152 . 
Reich PB (2014) The world-wide 'fast-slow' plant economics spectrum: a traits manifesto. Journal of Ecology, 102:275-301.

Resh SC, Worledge D, Battaglia D \& Ladiges S (2003) Coarse root biomass for eucalypt plantations in Tasmania, Australia: sources of variation and methods of assessment. Trees, 17:389-399.

Rosenvald K, Ostonen I, URI V, Varik M, Tedersoo L \& Lõhmus K (2013) Tree age effect on fine-root and leaf morphology in a silver birch forest chronosequence. European Journal of Forest Research, 132:219-230.
Tyree MT, Velez V \& Dalling JW (1998) Growth dynamics of root and shoot hydraulic conductance in seedlings of five neotropical tree species: scaling to show possible adaptation to differing light regimes. Oecologia, 114:293-298.

Waring RH, Coops NC, Mathys A, Hilker T \& Latta G (2014) Process-Based Modeling to Assess the Effects of Recent Climatic Variation on Site Productivity and Forest Function across Western North America. Forests, 3:518-534.

Withington JM, Reich PB, Oleksyn J \& Eissenstat DM (2006) Comparisons of structure and life span in roots and leaves among temperate trees. Ecological Monographs, 76:381-397. 